\title{
EFEKTIVITAS BUAH PEPAYA TERHADAP PENURUNAN INDEKS PLAK PADA SISWA/I KELAS VII-2 DI SMP N 1 BATANG KUIS KABUPATEN DELI SERDANG TAHUN 2017
}

\author{
Netty Jojor Aritonang \\ Jurusan Keperawatan Gigi Politeknik Kesehatan Kemenkes RI Medan
}

\begin{abstract}
Fibrous fruit which contains a lot of water can be consumed as tooth cleaner which can remove plaque from tooth surface. The result of the laboratory research revealed that $20 \%$ of plaque consists of organic and nonorganic solid substance and $80 \%$ of the plaque weight consists of water and $70 \%$ of the solid substance consists of microorganism. The research was a descriptive survey. It was conducted on Grade VII-2 students of SMP N 1 Batang Kuis, Deli Serdang Regency. The population was 216 students, and 35 of them were used as the samples. The result of the research showed that after chewing papaya, 15 respondents had good criteria in their plaque index, 20 respondents had moderate criteria, and no respondent had bad criteria.The conclusion was that the mean difference in plaque index before and after chewing papaya influenced the decrease in plaque index which could be seen from the mean difference in plaque index before and after chewing papaya.
\end{abstract}

Keywords : Papaya, Decreasing in Plaque Index

\section{PENDAHULUAN}

Data dari PDGI (Persatuan Dokter Gigi Indonesia) menyebutkan $69,3 \%$ dari orang Indonesia yang mengeluh sakit gigi berupaya mengobatinya sendiri dengan cara yang belum tentu benar. Ada yang menggunakan getah bunga Kamboja. Ada yang manambal lubang pada gigi dengan menggunakan pasta gigi. Ada juga yang menggunakan kapas yang sebelumnya ditetesi minyak kelapa. Padahal, perawatan dan pengobatan yang tidak tepat, bukan saja tidak menyembuhkan tetapi dapat pula memicu penyakit lain yang lebih berbahaya seperti sakit kepala, nyeri mata, jantung, stroke, diabetes bahkan kelahiran prematur (Yekti Mumpuni, 2013).

Dari hasil penelitian laboratorium diketahui $20 \%$ dari pada plak gigi terdiri atas bahan padat organik dan anorganik dan $80 \%$ dari berat plak gigi terdiri dari air dan $70 \%$ bahan padat terdiri atas mikroorganisme (Monang Panjaitan).

Berdasarkan uraian diatas, penulis ingin melakukan penelitian mengenai "Efektivitas Buah Pepaya Terhadap Penurunan Indeks Plak Pada Siswa/i Kelas VII-2 di SMP Negeri 1 Batang Kuis Kabupaten Deli Serdang Tahun 2017".

\section{Tujuan Penelitian}

Untuk mengetahui efektivitas buah pepaya terhadap penurunan indeks plak pada siswa/i kelas VII2 di SMP Negeri 1 Batang Kuis Kabupaten Deli Serdang tahun 2017.
Manfaat Penelitian

1. Siswa/i dapat mengetahui bahwa buah pepaya dapat menurunkan indeks plak.

2. Memberikan informasi tambahan bagi pengembangan ilmu pengetahuan khususnya ilmu kesehatan gigi dan mulut.

3. Hasil penelitian diharapkan menambah wawasan dan ilmu pengetahuan gigi pada indeks plak siswa/i kelas VII-2 di SMP N 1 Batang Kuis.

\section{Metode Penelitian}

Jenis penelitian yang akan dilakukan adalah penelitian deskriptif dengan metode survey yaitu untuk mengetahui peranan buah Pepaya terhadap penurunan indeks plak pada Siswa/i kelas VII-2 di SMP N 1 Batang Kuis Kabupaten Deli Serdang Tahun 2017.

\section{Populasi dan Sampel Penelitian}

populasi dalam penelitian ini seluruh siswa/i kelas VII-2 SMP N 1 Batang Kuis Kabupaten Deli Serdang Tahun 2017, dengan jumlah 216 orang.

Dalam penelitian ini sampel penelitian adalah kelas VII-2 SMP N 1 dengan jumlah 35 orang.

\section{HASIL DAN PEMBAHASAN}

\section{Hasil Penelitian}

Data yang dikumpulkan adalah hasil penelitian yang dilakukan terhadap siswa/i kelas VII-2 SMP N 1 Batang Kuis Kabupaten Deli Serdang Tahun 2017. 
Pengumpulan data dilakukan dengan pemeriksaan langsung kemulut siswa/i yang menjadi sampel. Setelah seluruh data terkumpul, maka dilakukan pengumpulan data kemudian di analisa dengan membuat table distribusi frekuensi sebagai berikut :

Tabel 1. Distribusi FrekuensiPersentase Indeks Plak Sebelum Mengunyah Buah Pepaya Pada 35 Siswa/i Kelas VII-2 SMP N 1 Batang Kuis Kabupaten Deli Serdang Tahun 2017.

\begin{tabular}{cccc}
\hline No & Kriteria Plak & $\mathrm{N}$ & $\%$ \\
\hline 1 & Baik & 0 & 0 \\
2 & Sedang & 0 & 0 \\
3 & Buruk & 35 & $100 \%$ \\
\hline Jumlah & & 35 & $100 \%$ \\
\hline
\end{tabular}

Dari tabel dan grafik diatas, dapat dilihat bahwa persentase indeks plak sebelum mengunyah buah pepaya tidak ditemukan siswa/i yang memiliki persentase indeks plak kriteria baik dan sedang, $100 \%$ siswa/i yang memiliki kriteria buruk

Tabel 2. Distribusi Frekuensi Persentase Indeks Plak Sesudah Mengunyah Buah Pepaya Pada 35 Siswa/i Kelas VII-2 SMP N 1 Batang Kuis Kabupaten Deli Serdang Tahun 2017

\begin{tabular}{cccc}
\hline No & Kriteria Plak & N & $\%$ \\
\hline 1 & Baik & 15 & 43 \\
2 & Sedang & 20 & 57 \\
3 & Buruk & 35 & 0 \\
\hline Jumlah & & 35 & $100 \%$ \\
\hline
\end{tabular}

Dari tabel dan grafik di atas dapat dilihat bahwa persentase indeks plak setelah mengunyah buah pepaya ditemukan 15 siswa/i yang memiliki persentase baik yaitu $43 \%$ dan 20 siswa/i yang memiliki persentase sedang yaitu $57 \%$.

Tabel 3. Distribusi Frekuensi Indeks Plak Rata-Rata Sesudah Mengunyah Buah Pepaya pada 35 Siswa/i Kelas VII-2 SMP N 1 Batang Kuis Kabupaten Deli Serdang Tahun 2017.

\begin{tabular}{lcrcc}
\hline No & Kriteria Plak & N & $\begin{array}{c}\text { Jumlah } \\
\text { Nilai Plak }\end{array}$ & $\begin{array}{c}\text { Plak } \\
\text { Rata }\end{array}$ \\
\hline 1 & Baik & 15 & 13 & 0,87 \\
2 & Sedang & 20 & 31,4 & 1,57 \\
3 & Buruk & 0 & 0 & 0 \\
\hline Jumlah & 35 & 44,4 & 2,44 \\
\hline
\end{tabular}

Dari tabel di atas dapat dilihat bahwa dari 35 siswa/i yang telah mengunyah buah pepaya ditemukan 15 siswa/i yang memiliki indeks plak dengan kategori baik, 20 siswa/i yang memiliki indeks plak dengan kategori sedang, sedangkan siswa/i yang memiliki kriteria buruk tidak ada. Maka rata-rata indeks plak adalah sebesar 1,26 yaitu pada kategori sedang.

\section{PEMBAHASAN}

Penelitian ini mengambil sampel 35 siswa/i kelas VII-2 di SMP N 1 Batang Kuis Kabupaten Deli Serdang Tahun 2017. Dari hasil penelitian yang telah didapatkan maka diketahui bahwa indeks plak rata-rata sesudah mengunyah buah pepaya rata-rata mempunyai kriteria sedang 1,57 pada 20 orang,banyak siswa/i yang memiliki angka indeks plak yang tinggi yang berarti rendahnya tingkat kebersihan gigi dan mulut. Hal ini mungkin disebabkan karena kurangnya pengetahuan cara menjaga kebersihan gigi dan mulut.

Plak adalah lapisan tipis dari mikroorganisme, sisa makanan dan bahan organik yang terbentuk di gigi, kadang-kadang juga ditemukan pada gusi dan lidah. Plak merupakan proses dari berbagai macam mikroorganisme pada permukaan gigi mulai erupsi dengan cepat akan dilindungi lapisan tipis glikoprotein yang disebut aequired pellicle. Glikoprotein didalam air ludah akan diserap dengan spesifik pada hidroksiapatit dan melekat erat pada permukaan gigi.

Gigi biofilm, lebih sering disebut sebagai plak gigi. Pada awalnya, biofilm cukup lunak untuk lepas dengan menggunakan kuku jari. Namun, mulai mengeras dalam waktu 48 jam dan dalam waktu sekitar 10 hari plak menjadi gigi kalkulus (karang gigi) keras dan sulit dihilangkan.

Berdasarkan hasil pemeriksaan yang telah dilakukan terhadap seluruh sampel diketahui bahwa seluruh sampel (100\%) memiliki kriteria indeks plak buruk sebelum mengunyah buah pepaya. Namun setelah mengunyah buah pepaya, kriteria indeks plak berubah menjadi $57 \%$.

Hasil penelitian ini dapat diketahui bahwa buah pepaya dapat digunakan untuk menurunkan angka indeks plak. Faktor lain yang juga harus diperhatikan yang dapat menjaga kebersihan gigi dan mulut atau indeks plak adalah menyikat gigi minimal dua kali sehari dan memeriksa gigi kedokter gigi secara berkala. Makanan yang keras, kasar dan berserat juga menghalangi plak dan fakta ini sudah diteliti pada eksperimental.

\section{SIMPULAN DAN SARAN}

\section{Simpulan}

1. Indeks plak sebelum mengunyah buah pepaya memiliki kriteria indeks plak buruk dengan persentase $100 \%$, sesudah mengunyah buah pepaya indeks plak berubah menjadi kriteria baik dengan persentase $43 \%$ yaitu berjumlah 15 siswa/i, dan kriteria sedang dengan persentase $57 \%$ yaitu berjumlah 20 siswa/i.

2. Rata-rata indeks plak sebelum mengunyah buah Pepaya adalah buruk dengan rata-rata 2,45, sedangkan sesudah mengunyah buah pepaya rata-rata indeks plak menjadi 1,26 pada kategori sedang

\section{Saran}

1. Diharapkan kepada siswa/i kelas VII-2 SMP Negeri 1 Batang Kuis Kabupaten Deli Serdang supaya banyak 
mengkonsumsi buah pepaya agar dapat meningkatkan kebersihan gigi dan mulut.

2. Diharapkan kepada siswa/i kelas VII-2 SMP Negeri 1 Batang Kuis Kabupaten Deli Serdang menjaga kebersihan gigi dan mulutnya dengan cara menyikat gigi, melakukan pemeriksaan gigi secara berkala dan mengkonsumsi buah-buahan terutama mengkonsumsi buah pepaya.

3. Diharapkan kepada peneliti supaya banyak mengkonsumsi buah pepaya agar dapat meningkatkan kebersihan gigi dan mulut.

\section{DAFTAR PUSTAKA}

Aditiawarman, 2012. Kesehatan gigi dan mulut. Pustaka Reka Cipta, Bandung.

Arikunto, S. 2006. Prosedur Penelitian. Edisi Revisi VI. Jakarta : Rineka

Hongini, S.Y. 2012. Kesehatan Gigi dan Mulut. Bandung : Pustaka Reka Cipta

Houwink, B. 1993. Ilmu Kedokteran Gigi Pencegahan. Yogyakarta : Gadjah Mada Universitas Press

https://rlagista.wordpress.com/2013/12/01/plaks-indeks/

Jussawalla, J. 2006. Cara Natural Mencpai Kesehatan Prima. Jakarta : Prestasi Pustakaraya
Manson, J.D. 2012. Periodontitis. Edisi 2. Jakarta : EGC Mumpuni, Dr Yekti. 2013. 45 Masalah \& Solusi Penyakit Gigi Dan Mulut. Jogjakarta: Firtramaya.

Notoadmodjo, S 2005. Metodologi Penelitian Kesehatan. Cetakan ketiga. Jakarta: Rineka Cipta.

Panjaitan, M. 1995. Etiologi Karies Gigi dan Penyakit Periodontal. Edisi 1. Medan: USU PRESS

Roeslan, O.B., 2002. Imunologi oral kelainan dalam rongga mulut. Balai Penerbit FKUI, Jakarta.

Sabri, L. 2008. STATISTIK KESEHATAN

Tarigan, R. 2014. Karies Gigi. Edisi 2. Jakarta : EGC 